\title{
Comparing the clinical outcomes of young-onset and adult-onset ulcerative colitis: a multi-center Korean Association for the Study for Intestinal Diseases study
}

Ji Yeon Kim ${ }^{1}$, Dong Il Park ${ }^{1}$, Dong Soo Han ${ }^{2}$, Kyu-Chan Huh³, Chang Kyun Lee ${ }^{4}$, Jeong Eun Shin ${ }^{5}$, Jae Hak Kim ${ }^{6}$, You Sun Kim7, Yunho Jung ${ }^{8}$, Sung-Ae Jung ${ }^{9}$, Hyun Joo Song ${ }^{10}$, Hyun Joo Jang ${ }^{11}$, Young-Ho Kim ${ }^{12}$, and Sung No Hong ${ }^{12}$

\begin{abstract}
Department of Internal Medicine, ${ }^{1}$ Kangbuk Samsung Hospital, Sungkyunkwan University School of Medicine, Seoul; ${ }^{2}$ Hanyang University Guri Hospital, Guri; ${ }^{3}$ Konyang University College of Medicine, Daejeon; ${ }^{4}$ Kyung Hee University School of Medicine, Seoul; ${ }^{5}$ Dankook University College of Medicine, Cheonan; ${ }^{6}$ Dongguk University College of Medicine, Gyeongju; ${ }^{7}$ Inje University College of Medicine, Busan; ${ }^{8}$ Soonchunhyang University College of Medicine, Asan; ${ }^{9}$ Ewha Womans University School of Medicine, Seoul; ${ }^{10}$ Jeju National University College of Medicine, Jeju; ${ }^{11} \mathrm{Hallym}$ University College of Medicine, Chuncheon; ${ }^{12}$ Samsung Medical Center, Sungkyunkwan University School of Medicine, Seoul, Korea
\end{abstract}

\author{
Received: August 31, 2014 \\ Revised : November 10, 2014 \\ Accepted: September 1, 2015

\section{Correspondence to} \\ Dong Il Park, M.D. \\ Department of Internal Medicine, \\ Kangbuk Samsung Hospital, \\ Sungkyunkwan University School \\ of Medicine, 29 Saemunan-ro, \\ Jongno-gu, Seoul 03181, Korea \\ Tel: +82-2-2001-2059 \\ Fax: +82-2-2001-2049 \\ E-mail: diksmc.park@samsung.com
}

Background/Aims: The aim of this study was to compare the clinical features and outcomes of ulcerative colitis (UC) according to the age of onset in Korea. Methods: A total of 1,141 patients who were diagnosed with UC between July 1987 and November 2013 at 11 tertiary hospitals were enrolled. The baseline disease characteristic and disease state at onset, treatment during the disease course were retrospectively reviewed among patients with young-onset $(\mathrm{YO},<20$ years) and adult-onset $(\mathrm{AO}, \geq 20$ years). Severe outcome was defined as use of intravenous (IV) steroids, infliximab, immunosuppressant, or UC-related operation.

Results: There were 55 YO patients (mean age, $17.8 \pm 2.4$ ) and 1,086 AO patients (mean age, $43.0 \pm 13.6)$. High Mayo scores ( $7.7 \pm 3.0$ vs. $5.6 \pm 2.7, p=0.000$ ), extensive UC ( $52.7 \%$ vs. $25.8 \%, p=0.000)$ and IV steroid ( $41.8 \%$ vs. $18.0 \%, p=0.000$ ), immunosuppressant ( $47.3 \%$ vs. $26.9 \%, p=0.002)$, and infliximab (20.0\% vs. $7.2 \%$, $p=0.001)$ use were more frequent in the YO than in the AO group. According to multivariate analysis, severe outcomes were related to YO disease (hazard ratio [HR], 2.18; 95\% confidence interval [CI], 1.27 to 3.71$)$, body mass index $<23 \mathrm{~kg} / \mathrm{m}^{2}$ (HR, 1.46; 95\% CI, 1.07 to 2.00), severe (HR, 2.29; $95 \%$ CI, 1.36 to 3.38 ), and moderate (HR, 2.48; $95 \%$ CI, 1.67 to 3.67) disease, extensive UC (HR, 2.90; $95 \%$ CI, 1.79 to 4.69), UC-related admission (HR, 63.89; 95\% CI, 20.41 to 200.02), and oral steroid use (HR, $0.51 ; 95 \%$ CI, 0.39 to 0.67 ).

Conclusions: UC with YO presented with more advanced clinical features at onset and more severe outcomes than the AO. YO cases require careful management and intense treatment strategies.

Keywords: Colitis, ulcerative; Young-onset; Clinical feature; Outcome 


\section{INTRODUCTION}

Ulcerative colitis (UC) is a chronic and relapsing inflammatory disease of the colon and rectum that affects continuously. Although its exact etiology remains unknown, $\mathrm{UC}$ is thought to arise from an interaction between genetic and environmental factors. Given its chronic and relapsing nature, UC can seriously impact quality of life [1].

The worldwide incidence of UC varies greatly according to geographic location. The prevalence ranges between 0.5 and 24.5 per 100,000 persons [2]. The annual incidence of UC in Asia is lower than that in Western regions $[3,4]$. However, the incidence of UC has increased in Asian countries secondary to the westernization of lifestyle and diagnostic modalities [5,6], especially among the younger age patients [7]. Due to these changes, UC is expected to become an increasing a clinical burden in Asia.

UC has bimodal peaks for incidence. There is a small peak in incidence around the age of 20 years and a second larger peak around the age of 60 years [8]. Recently, it was recognized that clinical characteristics and disease outcomes differ according to the age of diagnosis. However, these studies have shown conflicting results. Some studies have found that early-onset UC produce a more severe phenotype [9] and requires more frequent operation than does late-onset UC [10]. Additionally, a larger proportion of patients with pediatric-onset UC require immunosuppressive and biologic agents compared to those with adult-onset (AO) disease [11]. In contrast, late-onset UC is related to refractoriness to therapy [12] and aggressive development of colorectal cancer [13]. Another study reported that age at diagnosis had no effect on prognosis [14].

In Korea, the clinical differences and effects related to age of onset in patients with UC have not been well established. A previous study reported that certain clinical features and disease extent more severe when UC is diagnosed at a younger age, as compared to when it is diagnosed later in life. However, the disease course and prognosis may not differ from those of their older counterparts [15]. Given this background, the aim of the present study was to compare the clinical features and disease outcomes of UC according to the age of onset in Korea.

\section{METHODS}

\section{Study population}

This is a multi-center, retrospective cohort study. Korean patients who were diagnosed with UC between July 1987 and November 2013 at one of 11 tertiary hospitals were identified. All patients were diagnosed and treated by inflammatory bowel disease (IBD) specialists who are members of the Korean Association for the Study for Intestinal Diseases. The diagnosis of UC was based on accepted clinical, endoscopic, and histological findings [16]. Patients with the following conditions were excluded: incomplete medical records or diagnosis of other type of colitis including Crohn disease (CD), Behcet's disease, or infectious colitis. The study population was classified into two groups according to the age of onset. Patients who were diagnosed before the age of 20 years were defined as the young-onset (YO) group and those diagnosed at or after the age of 20 years were assigned to the AO group. This study was approved by the Institutional Review Board of each participating hospital.

\section{Data collection and clinical outcomes}

The baseline patient characteristics and clinical information were collected retrospectively from the medical records of each participating hospital. The baseline characteristics included age at diagnosis, gender, body mass index (BMI), family history of IBD, smoking status, and follow-up duration. The disease state at diagnosis, including the Mayo score and the extent of disease, was also evaluated. The Mayo score is a 13-scale index (o to 12) that represents disease activity including stool frequency, rectal bleeding, endoscopic findings, and a physician's overall assessment [17]. The disease activity at diagnosis was measured using the Mayo score. A Mayo score of 3 to 5 was considered mild disease, 6 to 10 was moderate disease and 11 to 12 was severe disease. The extent of disease was determined by endoscopic findings and was categorized into three groups using the Montreal classification [18]. A lesion extending from the anal verge to the rectosigmoid junction was defined as ulcerative proctitis, disease to the distal part of the splenic flexure was defined as left-sided colitis and disease that extended beyond the splenic flexure was defined as extensive colitis. Each patients' treatment during disease course were assessed according to the history of UC-re- 
lated admission and operation and, prior use of oral steroids, intravenous (IV) steroids, immunosuppressants, or infliximab. A history of oral steroid use was limited to independent cases of IV steroid use. Severe outcomes were defined by the use of IV steroids, infliximab, immunosuppressants or UC-related operation.

\section{Statistical analysis}

SPSS version 18.0 (SPSS Inc., Chicago, IL, USA) was used for all statistical analyses. The chi-square test or Fisher exact test was used for the analysis of categorical variables, such as gender, smoking status, disease activity at diagnosis, extent of disease, UC-related admission, UC-related operation, and medication use. Continuous variables including age, BMI, duration of follow-up, and Mayo score were analyzed using Student $t$ test. Kaplan-Meier survival analysis was performed to identify factors associated with outcomes, and the log-rank test was used to evaluate any significant differences according to each factor. Multivariate analysis using Cox proportional hazard regression was used to determine independent predictive factors, and these results were estimated using hazard ratios (HRs) and 95\% confidence intervals (CIs). In multivariate analysis, baseline characteristics at diagnosis were analyzed without treatment-related factors in order to evaluate factors affecting outcomes. The factors associated with treatment were analyzed using all variables. Results were considered statistically significant when $p$ values were $<0.05$.

\section{RESULTS}

\section{Clinical characteristics and outcomes of the study population}

A total of 1,141 patients with UC were included in the present study. The baseline patient characteristics are described in Table 1 . The mean age at diagnosis was $41.8 \pm 14.3$ years and the mean duration of follow-up was $7.1 \pm 4.2$ years. Overall, 645 patients $(56.5 \%)$ were male. Most patients were diagnosed with mild disease activity (52.3\%) and ulcerative proctitis (43.9\%). Furthermore, $41.4 \%$ of patients were hospitalized for UC treatment and $5.5 \%$ underwent operation. The $43.2 \%$ of patients used oral steroid independently for treatment of UC.

\section{Comparison by age of onset}

A total of 55 patients (4.8\%) were diagnosed with YO disease and 1,086 patients (95.2\%) had AO disease. The mean age at diagnosis was $17.8 \pm 2.4$ years in the YO group and $43.0 \pm 13.6$ years in the AO group. The mean BMI was significantly lower in the YO group than it was in the AO group $\left(19.8 \pm 2.8 \mathrm{~kg} / \mathrm{m}^{2}\right.$ vs. $22.4 \pm 3.1 \mathrm{~kg} / \mathrm{m}^{2}, p=$ 0.000). Patients in the YO group smoked less frequently than those in the AO group (5.6\% vs. $25.3 \%, p=0.007$ ). At the time of diagnosis, the YO group presented with a higher mean Mayo score than did the AO group (7.7 \pm 3.0 vs. $5.6 \pm 2.7, p=0.000$ ). Severe disease activity and

Table 1. Baseline patient characteristics

\begin{tabular}{|c|c|}
\hline Characteristic & $\begin{array}{c}\text { Total patients } \\
\text { with UC }(n=1,141)\end{array}$ \\
\hline Age at diagnosis, yr & $41.8 \pm 14.3$ \\
\hline \multicolumn{2}{|l|}{ Sex } \\
\hline Male & $645(56.5)$ \\
\hline Female & $496(43.5)$ \\
\hline Body mass index, $\mathrm{kg} / \mathrm{m}^{2}$ & $22.3 \pm 3.1$ \\
\hline Family history of IBD & $13 / 918(1.4)$ \\
\hline Smoking & $186 / 762(24.4)$ \\
\hline Follow-up duration, yr & $7.1 \pm 4.2$ \\
\hline Mayo score at diagnosis & $5.7 \pm 2.8$ \\
\hline \multicolumn{2}{|l|}{ Disease activity at diagnosis } \\
\hline Mild & $398 / 761(52.3)$ \\
\hline Moderate & $278 / 761(36.5)$ \\
\hline Severe & $85 / 761(11.2)$ \\
\hline \multicolumn{2}{|l|}{$\begin{array}{l}\text { Montreal classification of } \\
\text { extent of UC }\end{array}$} \\
\hline E1 (ulcerative proctitis) & $501(43.9)$ \\
\hline E2 (left-sided UC) & $331(29.0)$ \\
\hline E3 (extensive UC) & $309(27.1)$ \\
\hline UC-related admission & $472(41.4)$ \\
\hline UC-related operation & $63(5 \cdot 5)$ \\
\hline \multicolumn{2}{|l|}{ Medication } \\
\hline Oral steroids & $493(43.2)$ \\
\hline IV steroids & $219(19.2)$ \\
\hline Immunosuppressants & $318(27.9)$ \\
\hline Infliximab & $89(7.8)$ \\
\hline
\end{tabular}

Values are presented as mean \pm SD or number (\%). Patients with missing values were not included in analysis. Data are expressed as raw numbers with proportions.

UC, ulcerative colitis; IBD, inflammatory bowel disease; IV, intravenous. 
extensive UC at diagnosis were more frequent in the $\mathrm{YO}$ group than they were in the AO group (28.6\% vs. 10.3\%, $p$ $=0.000 ; 52.7 \%$ vs. $25.8 \%, p=0.000$, respectively) (Table 2 ).

During follow-up, there were no significant differences in UC-related admission or operation, or use of oral steroids between the two groups. However, IV steroids, immunosuppressants and infliximab were used more frequently in the YO group than they were in the AO group (41.8\% vs. $18.0 \%, p=0.000 ; 47.3 \%$ vs. $26.9 \%, p=$ $0.002 ; 20.0 \%$ vs. $7.2 \%, p=0.001$, respectively) (Table 2 ).

\section{Risk factors associated with severe outcomes}

Patients were more likely to require IV steroids if they were diagnosed before the age of 20 years (HR, 2.01; 95\%
CI, 1.27 to $3.85 ; p=0.005$ ). Use of infliximab (HR, 3.37; 95\% CI, 1.61 to $7.04 ; p=0.001$ ) and immunosuppressant (HR, 2.13; $95 \%$ CI, 1.22 to 3.70 ; $p=0.008$ ) were also more increased in the YO group. However, there was no relationship between UC-related operation and the age at diagnosis (Table 3). The results of univariate and multivariate analyses of the risk factors associated with IV steroids, infliximab and immunosuppressants use and UC-related operation are described in Supplementary Tables 1-5.

Table 4 and Fig. 1 describe the risk factors for severe outcomes. For the baseline characteristics at diagnosis, multivariate analysis identified that YO disease was significantly associated with increased risk of se-

Table 2. Baseline characteristics and outcomes by age of onset in ulcerative colitis patients

\begin{tabular}{|c|c|c|c|}
\hline Characteristic & Young-onset $(\mathrm{n}=55)$ & Adult-onset $(\mathrm{n}=1,086)$ & $p$ value \\
\hline Age at diagnosis, yr & $17.8 \pm 2.4$ & $43.0 \pm 13.6$ & 0.000 \\
\hline Sex & & & 0.560 \\
\hline Male & $29(52.7)$ & $616(56.7)$ & \\
\hline Female & $26(47 \cdot 3)$ & $470(43 \cdot 3)$ & \\
\hline Body mass index, kg/m² & $19.8 \pm 2.8$ & $22.4 \pm 3.1$ & 0.000 \\
\hline Body mass index $\geq 23 \mathrm{~kg} / \mathrm{m}^{2}$ & $7(12.7)$ & $446(41.1)$ & \\
\hline Family history of IBD & $1 / 45(2.2)$ & $12 / 886(1.4)$ & 0.628 \\
\hline Smoking & $2 / 36(5 \cdot 6)$ & $184 / 726(25 \cdot 3)$ & 0.007 \\
\hline Follow-up duration, yr & $7 \cdot 0 \pm 3 \cdot 9$ & $7.2 \pm 4.2$ & 0.819 \\
\hline Mayo score at diagnosis & $7 \cdot 7 \pm 3.0$ & $5.6 \pm 2.7$ & 0.000 \\
\hline Disease activity at diagnosis & & & 0.000 \\
\hline Mild & $8 / 35(22.9)$ & $390 / 726(53.7)$ & \\
\hline Moderate & $17 / 35(48.5)$ & $261 / 726(36.0)$ & \\
\hline Severe & $10 / 35(28.6)$ & $75 / 726(10.3)$ & \\
\hline Montreal classification of extent of UC & & & 0.000 \\
\hline E1 (ulcerative proctitis) & $15(27 \cdot 3)$ & $486(44.8)$ & \\
\hline E2 (left-sided UC) & $11(20.0)$ & $320(29 \cdot 5)$ & \\
\hline E3 (extensive UC) & $29(52.7)$ & $280(25.8)$ & \\
\hline UC-related admission & $29(52.7)$ & $443(40.8)$ & 0.080 \\
\hline UC-related operation & $4(7 \cdot 3)$ & $59(5 \cdot 4)$ & 0.560 \\
\hline \multicolumn{4}{|l|}{ Medication } \\
\hline Oral steroids & $19(34.5)$ & $474(43 \cdot 6)$ & 0.210 \\
\hline IV steroids & $23(41.8)$ & $196(18.0)$ & 0.000 \\
\hline Immunosuppressants & $26(47 \cdot 3)$ & $292(26.9)$ & 0.002 \\
\hline Infliximab & $11(20.0)$ & $78(7.2)$ & 0.001 \\
\hline
\end{tabular}

Values are presented as mean \pm SD or number (\%). Patients with missing values were not included. Data are expressed as raw numbers with proportions.

IBD, inflammatory bowel disease; UC, ulcerative colitis; IV, intravenous. 
Table 3. Associations between age of ulcerative colitis onset and severe outcomes

\begin{tabular}{|c|c|c|c|c|}
\hline \multirow{2}{*}{ Variable } & \multicolumn{2}{|c|}{ Univariate analysis } & \multicolumn{2}{|c|}{ Multivariate analysis } \\
\hline & 7-Year cumulative rate, \% & $p$ value & $\operatorname{HR}(95 \% \mathrm{CI})$ & $p$ value \\
\hline IV steroids, yr & & 0.000 & & \\
\hline$\geq 20$ & 15.0 & & Reference & \\
\hline$<20$ & 36.1 & & $2.01(1.27-3.85)$ & 0.005 \\
\hline Infliximab, yr & & 0.000 & & \\
\hline$\geq 20$ & 5.8 & & Reference & \\
\hline$<20$ & $14 \cdot 5$ & & $3.37(1.61-7.04)$ & 0.001 \\
\hline Immunosuppressants, yr & & 0.001 & & \\
\hline$\geq 20$ & 36.3 & & Reference & \\
\hline$<20$ & 19.0 & & $2.13(1.22-3.70)$ & 0.008 \\
\hline UC-related operation, yr & & 0.430 & & \\
\hline$\geq 20$ & $5 \cdot 7$ & & Reference & \\
\hline$<20$ & 5.1 & & $1.45(0.41-5.17)$ & 0.567 \\
\hline
\end{tabular}

HR, hazard ratio; CI, confidence interval; IV, intravenous; UC, ulcerative colitis.

vere outcomes (HR, 2.18; 95\% CI, 1.27 to $3.71 ; p=0.040$ ). In addition, $\mathrm{BMI}<23 \mathrm{~kg} / \mathrm{m}^{2}(\mathrm{HR}, 1.46 ; 95 \% \mathrm{CI}, 1.07$ to 2.00; $p=0.018)$, moderate (HR, 2.48; $95 \% \mathrm{CI}, 1.67$ to 3.67 ; $p=0.000$ ), and severe (HR, 2.29; 95\% CI, 1.36 to $3.38 ; p$ $=0.002$ ) disease activity at diagnosis, and extensive UC (HR, 2.90; 95\% CI, 1.79 to 4.69 ; $p=0.000$ ) were also related to increased risk of severe outcomes. During treatment, a history of UC-related admission (HR, 63.89; $95 \% \mathrm{CI}, 20.41$ to $200.02 ; p=0.000$ ) was related to severe outcomes. In contrast, previous use of oral steroids (HR, $0.51 ; 95 \% \mathrm{CI}, 0.39$ to $0.67 ; p=0.000$ ) decreased the risk of severe outcomes.

\section{DISCUSSION}

It is important to understand the clinical features and outcomes of UC with regard to the age of onset, because it may influence the proper treatment strategy to be used in clinical practice. The present study was the first large, multi-center and long-term study that analyzes the effects of age at disease onset. Our results suggest that age of onset is an important factor with regard to the clinical course of UC and, in particular, that clinical features and outcomes were more severe in UC patients with YO disease.

In the present study, we found that patients with YO disease had advanced clinical features at the time of di- agnosis. Upon diagnosis, approximately $30 \%$ of YO patients had severe disease activity and more than $50 \%$ had extensive UC. In contrast, $50 \%$ of the patients in the AO group were initially diagnosed with mild disease activity and proctitis. The risk of IV steroid, infliximab and immunosuppressants use was also higher in the YO patients than it was in the AO patients. A previous study reported that patients younger than 17 years of age at diagnosis had more extensive disease and aggressive clinical course, including steroid use than do those diagnosed after the age of 17 [9]. Previous population-based cohort studies have demonstrated that the number of relapses decreased with increasing age of onset [19]. In addition, a younger age at diagnosis has been found to be an independent predictor of earlier relapse, with an HR increase of 0.4 per decade [20]. Patients with late onset disease also have better responses to therapy and are more likely to experience steroid-free clinical remission 1 year after diagnosis than are patients with YO disease [21]. Overall, the results of the present study are consistent with those in the previous studies.

However, other reports have claimed that an older age of onset is related to poor outcomes in UC. A previous cross-sectional study found that patients 65 years and older were hospitalized more frequently and had higher in-hospital mortality and medical costs than did those diagnosed at a younger age [22]. However, this study was conducted using information from the Nationwide 
Table 4. Risk factors of severe outcomes of ulcerative colitis patients

\begin{tabular}{|c|c|c|c|c|}
\hline \multirow{2}{*}{ Characteristic } & \multicolumn{2}{|c|}{ Univariate analysis } & \multicolumn{2}{|c|}{ Multivariate analysis } \\
\hline & 7-Year cumulative rate, $\%$ & $p$ value & $\mathrm{HR}(95 \% \mathrm{CI})$ & $p$ value \\
\hline \multicolumn{5}{|l|}{ Baseline at diagnosis } \\
\hline Age, yr & & 0.001 & & \\
\hline$\geq 20$ & 19.1 & & Reference & \\
\hline$<20$ & 38.2 & & $2.18(1.27-3.71)$ & 0.040 \\
\hline Sex & & 0.536 & & \\
\hline Female & $19 \cdot 3$ & & Reference & \\
\hline Male & 20.5 & & $1.16(0.84-1.60)$ & 0.354 \\
\hline Body mass index, $\mathrm{kg} / \mathrm{m}^{2}$ & & 0.005 & & \\
\hline$\geq 23$ & $19 \cdot 3$ & & Reference & \\
\hline$<23$ & 26.5 & & $1.46(1.07-2.00)$ & 0.018 \\
\hline Family history of IBD & & 0.724 & & \\
\hline No & 24.8 & & Reference & \\
\hline Yes & 25.0 & & $2.28(0.71-7.34)$ & 0.165 \\
\hline Smoking status & & 0.053 & & \\
\hline No & 33.0 & & Reference & \\
\hline Yes & 23.7 & & $0.95(0.65-1.41)$ & 0.810 \\
\hline Disease activity at diagnosis & & 0.000 & & \\
\hline Mild & 14.2 & & Reference & \\
\hline Moderate & 46.9 & & $2.48(1.67-3.67)$ & 0.000 \\
\hline Severe & 49.8 & & $2.29(1.36-3.38)$ & 0.002 \\
\hline Montreal classification of extent of UC & & 0.000 & & \\
\hline E1 (ulcerative proctitis) & 6.7 & & Reference & \\
\hline E2 (left-sided UC) & 22.3 & & $1.38(0.85-2.24)$ & 0.197 \\
\hline E3 (extensive UC) & 39.8 & & $2.90(1.79-4.69)$ & 0.000 \\
\hline \multicolumn{5}{|l|}{ Treatment } \\
\hline UC-related admission & & 0.000 & & \\
\hline No & 2.4 & & Reference & \\
\hline Yes & 47.6 & & $63.89(20.41-200.02)$ & 0.000 \\
\hline \multicolumn{5}{|l|}{ Medication } \\
\hline Oral steroids & & 0.607 & & \\
\hline No & 31.1 & & Reference & \\
\hline Yes & 30.7 & & $0.51(0.39-0.67)$ & 0.000 \\
\hline
\end{tabular}

HR, hazard ratio; CI, confidence interval; IBD, inflammatory bowel disease; UC, ulcerative colitis.

Inpatient Samples; therefore, it is possible that their findings resulted from analysis of elderly patients with many comorbidities, and a secondary diagnosis of IBD. Similar results were seen in another population-based cohort study demonstrating that patients over the age of 50 at the time of diagnosis had increased mortality within the first two years of diagnosis than did those diagnosed at a younger age [23]. There were also more comorbidities reported in elderly patients, which were primarily attributed to their postoperative complications. Similarly, more severe outcomes and higher mortality in elderly UC patients observed in previous studies may not reflect UC itself.

It is controversial how the age of UC onset influences 


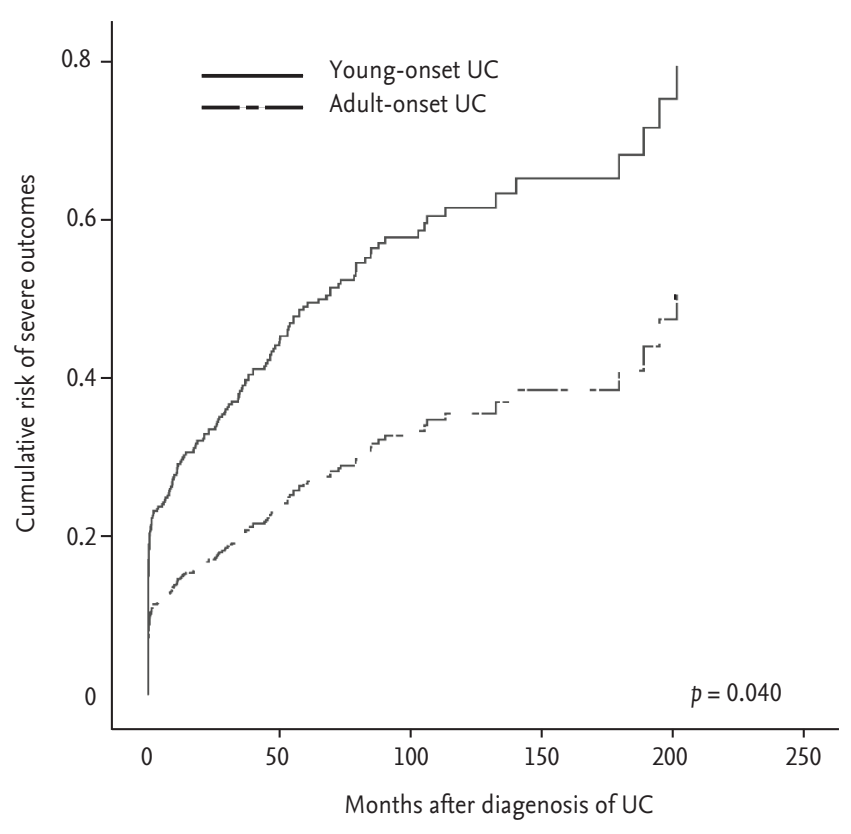

Figure 1. The cumulative risk of severe outcomes was higher in young-onset patients than it was in adult-onset patients $(p$ $=0.040)$. UC, ulcerative colitis.

the need for UC-related operation. Studies from Western countries have reported cumulative colectomy rates of $20 \%$ at 5 years and $25 \%$ at 10 years [24]. The rate of UC-related operation are lower in Asian patients than they are in Western patients, with a rate of $5.9 \%$ at 5 years and $10 \%$ of 10 years [25]. One Western study showed that the age of onset was younger in patients who had undergone previous operation [26]. The actuarial risk of colectomy in that study was $7.5 \%$ at 5 years and $10.4 \%$ at 10 years, higher than those of our study. Previous studies have suggested that the risk of operation does not differ by age of onset, with a previous study showing a higher proportion of steroid use in younger patients [27], although the other results were similar to ours. In our study, the UC-related operation rate was not significantly different between the two groups. This finding may reflect the fact that a top-down strategy including biologic agents was more frequently used in YO patients than in AO patients because of their more severe disease state upon diagnosis. Operation becomes necessary in UC when patients are medically refractory, or develop complications or colitic cancer. In the present study, extensive colitis at diagnosis was associated with an increased the risk of UC-related operation. Extensive inflammation may result in the development of complications and colitic cancer.

The reasons behind the severe clinical features at diagnosis and the severe outcomes in UC with YO are not clear. It is possible that YO patients are simply detected earlier because they present with more severe symptoms than do older patients. In patients with mild features and a relatively narrow extent, disease may not be recognized early and therefore, in these patients it is diagnosed later, when symptoms arise. A previous study suggested that the pathophysiologic mechanisms of YO and $\mathrm{AO}$ disease differ [28]. It has also been reported that YO was a poor prognostic factor for several autoimmune diseases, including systemic lupus erythematosus and type 1 diabetes mellitus [29], and that genetic factors are more highly associated with YO disease than they are with AO disease [30]. Mild disease UC with proctitis in AO patients may result from a weak immunologic reaction. Similar results have been observed in other immunologic diseases [31].

A previous report also demonstrated that treatment responses were better in UC patients with a BMI $<25$ $\mathrm{kg} / \mathrm{m}^{2}$ and in CD patients with a BMI $>25 \mathrm{~kg} / \mathrm{m}^{2}$ than they are in larger patients [32]. However, the relationship between UC and BMI has not been clearly established. Alterations in fat and muscle may affect bone health, muscle performance, quality of life, and overall morbidity. However, BMI does not accurately reflect body composition [33]. Interestingly, BMI $<23 \mathrm{~kg} / \mathrm{m}^{2}$ increased the risk of severe outcomes in the present study. The BMI in the YO group was lower than in the AO group in this study, which is consistent with the pattern observed in the general population by age. BMI reflects the nutritional status, which might be worse in patients with severe disease. Smoking, which has been shown to have a well-established protective effect against UC [19], was more common in the AO group than in the YO group. However, it did not affect disease outcomes in the present study. This finding may be related to the fact that most YO patients were minors, in whom smoking is prohibited. The association between smoking and UC does not appear to be very clear, as several other studies have argued that smoking does not have a protective effect against UC [34,35]. We also considered the finding that BMI and smoking increased with age. Further evaluation is needed to establish conclusive findings. 
This study has several limitations. There were only 55 YO patients (4.8\%) because data were collected from the Department of Internal Medicine's medical records. In addition, the mean age of YO patients was also relatively high, and pediatric UC patients were not included. Despite the small number of patients; however, there were significant differences in the severity of clinical features and outcomes between the two groups in the present study. Relapse rate is an important factor that affects disease course and severe outcomes in UC. Unfortunately, the relapse rate could not be determined in the present study. In addition, the results of outcomes analysis using patient history including UC-related admission and steroid use during follow-up after diagnosis of UC were limited because of inconsistent reference points. Further study is needed to confirm the associations and trends observed here.

UC is a relapsing and remitting disease, currently with no cure. The purpose of treatment UC is to maintain remission and prevent complications. Long-standing mucosal inflammation can lead to complications and colitic cancer. Patients with YO UC suffer from the disease for a longer period of time than do AO patients. It is possible that severe outcomes including operation may be higher in $\mathrm{YO}$ patients compared to in $\mathrm{AO}$ patients with a prolonged follow-up. Intensive care and uninterrupted follow-up are especially important for YO patients.

In conclusion, the present study revealed that age of disease onset has a major influence on UC. Patients with YO UC present with more advanced clinical features at diagnosis and experience more severe outcomes than do those with AO disease. Therefore, these results suggest that careful management and an intense treatment strategy are necessary for YO patients.

\section{KEY MESSAGE}

1. It has been previously reported that the age of onset affects the clinical features and course in patients with ulcerative colitis (UC).

2. The Mayo score was higher and there was more frequent extensive UC in young-onset (YO) disease group than there was in the adult-onset (AO) group. There was also more frequent intravenous steroid, infliximab and immunosuppressant use in the YO group than in the AO group.
However, there were no differences between YO and AO disease with regard to UC-related admission, operation or oral steroid use.

3. In Korea, compared to that of AO disease, YO UC presented with more advanced clinical features upon diagnosis, and more severe outcomes.

\section{Conflict of interest}

No potential conflict of interest relevant to this article was reported.

\section{Acknowledgments}

This work was funded by a grant of the Korean Health Technology R\&D Project, Ministry of Health and Welfare, Republic of Korea (A120176; DSH).

\section{REFERENCES}

1. Irvine EJ. Quality of life of patients with ulcerative colitis: past, present, and future. Inflamm Bowel Dis 2008;14:554565.

2. Cosnes J, Gower-Rousseau C, Seksik P, Cortot A. Epidemiology and natural history of inflammatory bowel diseases. Gastroenterology 2011;140:1785-1794.

3. Molodecky NA, Soon IS, Rabi DM, et al. Increasing incidence and prevalence of the inflammatory bowel diseases with time, based on systematic review. Gastroenterology 2012;142:46-54.e2.

4. Ng SC, Tang W, Ching JY, et al. Incidence and phenotype of inflammatory bowel disease based on results from the Asia-pacific Crohn's and colitis epidemiology study. Gastroenterology 2013;145:158-165.e2.

5. Yang DH, Yang SK. Trends in the incidence of ulcerative colitis in Korea. Korean J Med 2009;76:637-642.

6. Lok KH, Hung HG, Ng CH, et al. Epidemiology and clinical characteristics of ulcerative colitis in Chinese population: experience from a single center in Hong Kong. J Gastroenterol Hepatol 2008;23:406-410.

7. Shin DH, Sinn DH, Kim YH, et al. Increasing incidence of inflammatory bowel disease among young men in Korea between 2003 and 2008. Dig Dis Sci 2011;56:1154-1159.

8. Sonnenberg A. Age distribution of IBD hospitalization. Inflamm Bowel Dis 2010;16:452-457.

9. Kalkan IH, Dagli U, Oztas E, Tunc B, Ulker A. Compar- 
ison of demographic and clinical characteristics of patients with early vs. adult vs. late onset ulcerative colitis. Eur J Intern Med 2013;24:273-277.

10. Leijonmarck CE, Persson PG, Hellers G. Factors affecting colectomy rate in ulcerative colitis: an epidemiologic study. Gut 1990;31:329-333.

11. Adamiak T, Walkiewicz-Jedrzejczak D, Fish D, et al. Incidence, clinical characteristics, and natural history of pediatric IBD in Wisconsin: a population-based epidemiological study. Inflamm Bowel Dis 2013;19:1218-1223.

12. Zimmerman J, Gavish D, Rachmilewitz D. Early and late onset ulcerative colitis: distinct clinical features. J Clin Gastroenterol 1985;7:492-498.

13. Brackmann S, Andersen SN, Aamodt G, et al. Relationship between clinical parameters and the colitis-colorectal cancer interval in a cohort of patients with colorectal cancer in inflammatory bowel disease. Scand J Gastroenterol 2009;44:46-55.

14. Bresci G, Parisi G, Bertoni M, Capria A. Long-term maintenance treatment in ulcerative colitis: a 10-year follow-up. Dig Liver Dis 2002;34:419-423.

15. Lee JH, Cheon JH, Moon CM, et al. Do patients with ulcerative colitis diagnosed at a young age have more severe disease activity than patients diagnosed when older? Digestion 2010;81:237-243.

16. Lennard-Jones JE. Classification of inflammatory bowel disease. Scand J Gastroenterol Suppl 1989;170:2-6.

17. Schroeder KW, Tremaine WJ, Ilstrup DM. Coated oral 5-aminosalicylic acid therapy for mildly to moderately active ulcerative colitis: a randomized study. N Engl J Med 1987;317:1625-1629.

18. Silverberg MS, Satsangi J, Ahmad T, et al. Toward an integrated clinical, molecular and serological classification of inflammatory bowel disease: report of a Working Party of the 2005 Montreal World Congress of Gastroenterology. Can J Gastroenterol 2005;19 Suppl A:5A-36A.

19. Hoie O, Wolters F, Riis L, et al. Ulcerative colitis: patient characteristics may predict 10-yr disease recurrence in a European-wide population-based cohort. Am J Gastroenterol 2007;102:1692-1701.

20. Bitton A, Peppercorn MA, Antonioli DA, et al. Clinical, biological, and histologic parameters as predictors of relapse in ulcerative colitis. Gastroenterology 2001;120:1320.

21. Ha CY, Newberry RD, Stone CD, Ciorba MA. Patients with late-adult-onset ulcerative colitis have better outcomes than those with early onset disease. Clin Gastroenterol Hepatol 2010;8:682-687.e1.

22. Ananthakrishnan AN, McGinley EL, Binion DG. Inflammatory bowel disease in the elderly is associated with worse outcomes: a national study of hospitalizations. Inflamm Bowel Dis 2009;15:182-189.

23. Winther KV, Jess T, Langholz E, Munkholm P, Binder V. Survival and cause-specific mortality in ulcerative colitis: follow-up of a population-based cohort in Copenhagen County. Gastroenterology 2003;125:1576-1582.

24. Prideaux L, Kamm MA, De Cruz PP, Chan FK, Ng SC. Inflammatory bowel disease in Asia: a systematic review. J Gastroenterol Hepatol 2012;27:1266-1280.

25. Hilmi I, Singh R, Ganesananthan S, et al. Demography and clinical course of ulcerative colitis in a multiracial Asian population: a nationwide study from Malaysia. J Dig Dis 2009;10:15-20.

26. Targownik LE, Singh H, Nugent Z, Bernstein CN. The epidemiology of colectomy in ulcerative colitis: results from a population-based cohort. Am J Gastroenterol 2012;107:1228-1235.

27. Aloi M, Lionetti P, Barabino A, et al. Phenotype and disease course of early-onset pediatric inflammatory bowel disease. Inflamm Bowel Dis 2014;20:597-605.

28. Ekbom A, Helmick C, Zack M, Adami HO. Ulcerative proctitis in central Sweden 1965-1983: a population-based epidemiological study. Dig Dis Sci 1991;36:97-102.

29. Amador-Patarroyo MJ, Rodriguez-Rodriguez A, MontoyaOrtiz G. How does age at onset influence the outcome of autoimmune diseases? Autoimmune Dis 2012;2012:251730.

30. Grimm IS, Friedman LS. Inflammatory bowel disease in the elderly. Gastroenterol Clin North Am 1990;19:361-389.

31. Deal CL, Meenan RF, Goldenberg DL, et al. The clinical features of elderly-onset rheumatoid arthritis: a comparison with younger-onset disease of similar duration. Arthritis Rheum 1985;28:987-994.

32. Holtmann MH, Krummenauer F, Claas C, et al. Significant differences between Crohn's disease and ulcerative colitis regarding the impact of body mass index and initial disease activity on responsiveness to azathioprine: results from a European multicenter study in 1,176 patients. Dig Dis Sci 2010;55:1066-1078.

33. Bryant RV, Trott MJ, Bartholomeusz FD, Andrews JM. Systematic review: body composition in adults with inflammatory bowel disease. Aliment Pharmacol Ther 2013;38:213-225. 
34. Romberg-Camps MJ, Dagnelie PC, Kester AD, et al. Influence of phenotype at diagnosis and of other potential prognostic factors on the course of inflammatory bowel disease. Am J Gastroenterol 2009;104:371-383.
35. Roth LS, Chande N, Ponich T, Roth ML, Gregor J. Predictors of disease severity in ulcerative colitis patients from Southwestern Ontario. World J Gastroenterol 2010;16:232236. 
Supplementary Table 1. Baseline characteristics and outcomes by age of onset in ulcerative colitis patients

\begin{tabular}{|c|c|c|c|c|c|}
\hline \multirow{2}{*}{ Characteristic } & \multicolumn{4}{|c|}{ Age, yr } & \multirow{2}{*}{$p$ value } \\
\hline & $1-19(n=55)$ & $20-39(n=492)$ & $40-59(n=453)$ & $\geq 60(n=141)$ & \\
\hline Age of diagnosis, yr & $17.8 \pm 2.4$ & $30.9 \pm 5.4^{a}$ & $48.7 \pm 5 \cdot 3^{\mathrm{a}, \mathrm{b}}$ & $67 \cdot 0 \pm 5 \cdot 3^{\mathrm{a}, \mathrm{b}, \mathrm{c}}$ & 0.000 \\
\hline Sex & & & & & 0.938 \\
\hline Male & $29(52.7)$ & $277(56.3)$ & $259(57.2)$ & $80(56.7)$ & \\
\hline Female & $26(47 \cdot 3)$ & $215(43 \cdot 7)$ & $194(42.8)$ & $61(43 \cdot 3)$ & \\
\hline Body mass index, kg/m2 & $19.8 \pm 2.8$ & $21.8 \pm 3.0^{\mathrm{a}}$ & $22.9 \pm 3.1^{\mathrm{a}, \mathrm{b}}$ & $22.5 \pm 3.3^{\mathrm{a}, \mathrm{b}}$ & 0.243 \\
\hline Family history of IBD & $1 / 45(2.2)$ & $7 / 387(1.8)$ & $3 / 377(0.8)$ & $2 / 122(1.6)$ & 0.628 \\
\hline Smoking & $2 / 36(5 \cdot 6)$ & $68 / 317(21.5)^{\mathrm{a}}$ & $84 / 307(27.4)^{\mathrm{a}}$ & $32 / 102(31.4)^{\mathrm{a}, \mathrm{b}}$ & 0.006 \\
\hline Follow-up duration, yr & $7 \cdot 0 \pm 3 \cdot 9$ & $7 \cdot 4 \pm 4.2$ & $7.1 \pm 4 \cdot 3$ & $6.5 \pm 3.9$ & 0.624 \\
\hline Mayo score at diagnosis & $7 \cdot 7 \pm 3.0$ & $5.8 \pm 2.7^{\mathrm{a}}$ & $5 \cdot 4 \pm 2.7^{\mathrm{a}}$ & $5 \cdot 5 \pm 2.6^{a}$ & 0.389 \\
\hline Disease activity at diagnosis & & & & & 0.000 \\
\hline Mild (3-5) & $8 / 35(22.9)$ & $157 / 327(48.0)^{\mathrm{a}}$ & $183 / 305(60.0)^{\mathrm{a}, \mathrm{b}}$ & $50 / 94(53.2)^{\mathrm{a}}$ & \\
\hline Moderate (6-10) & $17 / 35(48.6)$ & $132 / 327(40.4)$ & $91 / 305(29.8)^{b}$ & $38 / 94(40.4)$ & \\
\hline Severe $(11-12)$ & $10 / 35(28.6)$ & $38 / 327(11.6)^{\mathrm{a}}$ & $31 / 305(10.2)^{\mathrm{a}}$ & $6 / 94(6.4)^{\mathrm{a}}$ & \\
\hline $\begin{array}{l}\text { Montreal classification of } \\
\text { extent of UC }\end{array}$ & & & & & 0.000 \\
\hline E1 (ulcerative proctitis) & $15(27 \cdot 3)$ & $209(42.5)^{\mathrm{a}}$ & $210(46.4)^{\mathrm{a}}$ & $67(47.5)^{\mathrm{a}}$ & \\
\hline E2 (left-sided UC) & $11(20.0)$ & $128(26.0)$ & $144(31.8)$ & $48(34.0)$ & \\
\hline E3 (extensive UC) & $29(52.7)$ & $155(31.5)^{\mathrm{a}}$ & $99(21.9)^{a, b}$ & $26(18.5)^{\mathrm{a}, \mathrm{b}}$ & \\
\hline UC-related admission & $29(52.7)$ & $192(39.0)$ & $186(41.1)$ & $65(46.1)$ & 0.147 \\
\hline UC-related operation & $4(7 \cdot 3)$ & $22(4 \cdot 5)$ & $27(6.0)$ & $10(7.1)$ & 0.533 \\
\hline \multicolumn{6}{|l|}{ Medication } \\
\hline Oral steroids & $19(34.5)$ & $212(43.1)$ & $206(45 \cdot 5)$ & $56(39.7)$ & 0.343 \\
\hline IV steroids & $23(41.8)$ & $95(19 \cdot 3)^{\mathrm{a}}$ & $70(15 \cdot 5)^{\mathrm{a}}$ & $31(22.0)^{\mathrm{a}}$ & 0.000 \\
\hline Immunosuppressants & $26(47 \cdot 3)$ & $146(29.7)^{\mathrm{a}}$ & $111(24.5)^{\mathrm{a}}$ & $35(24.8)^{a}$ & 0.003 \\
\hline Infliximab & $11(20.0)$ & $40(8.1)^{\mathrm{a}}$ & $31(6.8)^{\mathrm{a}}$ & $7(5 \cdot 0)^{\mathrm{a}}$ & 0.003 \\
\hline Severe outcomes & $24(43.6)$ & $122(24.8)^{\mathrm{a}}$ & $97(21.4)^{\mathrm{a}}$ & $37(26.2)^{\mathrm{a}}$ & 0.004 \\
\hline
\end{tabular}

Values are presented as mean \pm SD or number $(\%)$.

IBD, inflammatory bowel disease; UC, ulcerative colitis; IV, intravenous.

${ }^{a} p<0.05$ compared with the $1-19$ group.

${ }^{\mathrm{b}} p<0.05$ compared with the $20-39$ group.

${ }^{c} p<0.05$ compared with the 40-59 group. 
Supplementary Table 2. Risk factors of intravenous steroid use in ulcerative colitis patients

\begin{tabular}{|c|c|c|c|c|}
\hline \multirow{2}{*}{ Characteristic } & \multicolumn{2}{|c|}{ Univariate analysis } & \multicolumn{2}{|c|}{ Multivariate analysis } \\
\hline & 7-Year cumulative rate, $\%$ & $p$ value & $\operatorname{HR}(95 \% \mathrm{CI})$ & $p$ value \\
\hline \multicolumn{5}{|l|}{ Baseline at diagnosis } \\
\hline Age, yr & & 0.000 & & \\
\hline$\geq 20$ & $15 \cdot 0$ & & Reference & \\
\hline$<20$ & 36.1 & & $2.01(1.27-3.85)$ & 0.005 \\
\hline Sex & & 0.834 & & \\
\hline Female & 16.5 & & Reference & \\
\hline Male & $15 \cdot 6$ & & $1.01(0.71-1.42)$ & 0.976 \\
\hline Body mass index, $\mathrm{kg} / \mathrm{m}^{2}$ & & 0.021 & & \\
\hline$\geq 23$ & $15 \cdot 5$ & & Reference & \\
\hline$<23$ & 21.4 & & $1.45(1.03-2.04)$ & 0.035 \\
\hline Family history of IBD & & 0.600 & & \\
\hline No & 19.9 & & Reference & \\
\hline Yes & 23.1 & & $2.16(0.67-7.00)$ & 0.199 \\
\hline Smoking status & & 0.032 & & \\
\hline No & 27.2 & & Reference & \\
\hline Yes & 17.8 & & $0.96(0.62-1.48)$ & 0.848 \\
\hline Disease activity at diagnosis & & 0.000 & & \\
\hline Mild & 11.1 & & Reference & \\
\hline Moderate & $39 \cdot 7$ & & $2.48(1.61-3.82)$ & 0.000 \\
\hline Severe & $35 \cdot 3$ & & $1.78(1.01-3.14)$ & 0.048 \\
\hline Montreal classification of extent of UC & & 0.000 & & \\
\hline E1 (ulcerative proctitis) & $4 \cdot 9$ & & Reference & \\
\hline E2 (left-sided UC) & 16.8 & & $1.44(0.83-2.50)$ & 0.200 \\
\hline E3 (extensive UC) & $33 \cdot 7$ & & $3.53(2.06-6.04)$ & 0.000 \\
\hline \multicolumn{5}{|l|}{ Treatment } \\
\hline UC-related admission & & 0.000 & & \\
\hline No & 0.8 & & Reference & \\
\hline Yes & 38.9 & & $28.61(8.95-91.50)$ & 0.000 \\
\hline UC-related operation & & 0.000 & & \\
\hline No & $14 \cdot 5$ & & Reference & \\
\hline Yes & 41.3 & & $1.62(0.95-2.75)$ & 0.075 \\
\hline \multicolumn{5}{|l|}{ Medication } \\
\hline Oral steroids & & 0.000 & & \\
\hline No & 20.0 & & Reference & \\
\hline Yes & 11.1 & & $0.26(0.18-0.37)$ & 0.000 \\
\hline Immunosuppressants & & 0.000 & & \\
\hline No & $7 \cdot 9$ & & Reference & \\
\hline Yes & 48.7 & & $2.40(1.70-3.39)$ & 0.000 \\
\hline Infliximab & & 0.000 & & \\
\hline No & 13.1 & & Reference & \\
\hline Yes & 60.5 & & $1.22(0.81-1.84)$ & 0.349 \\
\hline
\end{tabular}

HR, hazard ratio; CI, confidence interval; IBD, inflammatory bowel disease; UC, ulcerative colitis. 
Supplementary Table 3. Risk factors of infliximab use in ulcerative colitis patients

\begin{tabular}{|c|c|c|c|c|}
\hline \multirow{2}{*}{ Characteristic } & \multicolumn{2}{|c|}{ Univariate analysis } & \multicolumn{2}{|c|}{ Multivariate analysis } \\
\hline & 7-Year cumulative rate, $\%$ & $p$ value & $\operatorname{HR}(95 \% \mathrm{CI})$ & $p$ value \\
\hline \multicolumn{5}{|l|}{ Baseline at diagnosis } \\
\hline Age, yr & & 0.000 & & \\
\hline$\geq 20$ & 5.8 & & Reference & \\
\hline$<20$ & 14.5 & & $3.37(1.61-7.04)$ & 0.001 \\
\hline Sex & & 0.070 & & \\
\hline Female & $5 \cdot 0$ & & Reference & \\
\hline Male & 7.1 & & $1.54(0.86-2.74)$ & 0.147 \\
\hline Body mass index, $\mathrm{kg} / \mathrm{m}^{2}$ & & 0.122 & & \\
\hline$\geq 23$ & 6.6 & & Reference & \\
\hline$<23$ & $7 \cdot 4$ & & $1.40(0.78-2.53)$ & 0.258 \\
\hline Family history of IBD & & 0.228 & & \\
\hline No & 7.6 & & Reference & \\
\hline Yes & 13.0 & & $1.82(0.42-7.96)$ & 0.428 \\
\hline Smoking status & & 0.550 & & \\
\hline No & 10.3 & & Reference & \\
\hline Yes & $7 \cdot 4$ & & $1.11(0.54-2.19)$ & 0.775 \\
\hline Disease activity at diagnosis & & 0.000 & & \\
\hline Mild & 4.0 & & Reference & \\
\hline Moderate & 17.5 & & $3.00(1.58-5.73)$ & 0.001 \\
\hline Severe & 13.7 & & $2.52(1.08-5.90)$ & 0.034 \\
\hline Montreal classification of extent of UC & & 0.000 & & \\
\hline E1 (ulcerative proctitis) & 2.0 & & Reference & \\
\hline E2 (left-sided UC) & 9.8 & & $1.43(0.58-3.51)$ & 0.437 \\
\hline $\mathrm{E}_{3}$ (extensive UC) & 8.9 & & $1.39(0.54-3.56)$ & 0.495 \\
\hline \multicolumn{5}{|l|}{ Treatment } \\
\hline UC-related admission & & 0.000 & & \\
\hline No & 2.0 & & Reference & \\
\hline Yes & 12.3 & & $1.17(0.48-2.89)$ & 0.729 \\
\hline UC-related operation & & 0.124 & & \\
\hline No & 6.5 & & Reference & \\
\hline Yes & 1.7 & & $0.14(0.02-1.02)$ & 0.069 \\
\hline \multicolumn{5}{|l|}{ Medication } \\
\hline Oral steroids & & 0.067 & & \\
\hline No & 4.6 & & Reference & \\
\hline Yes & 8.0 & & $1.49(0.80-2.79)$ & 0.210 \\
\hline IV steroids & & 0.000 & & \\
\hline No & 2.8 & & Reference & \\
\hline Yes & 22.0 & & $2.01(1.09-3.69)$ & 0.024 \\
\hline Immunosuppressants & & 0.000 & & \\
\hline No & 0.6 & & Reference & \\
\hline Yes & $17 \cdot 3$ & & $12.29(4.70-32.11)$ & 0.000 \\
\hline
\end{tabular}

HR, hazard ratio; CI, confidence interval; IBD, inflammatory bowel disease; UC, ulcerative colitis; IV, intravenous. 
Supplementary Table 4. Risk factors of immunosuppressant use in ulcerative colitis patients

\begin{tabular}{|c|c|c|c|c|}
\hline \multirow{2}{*}{ Characteristic } & \multicolumn{2}{|c|}{ Univariate analysis } & \multicolumn{2}{|c|}{ Multivariate analysis } \\
\hline & 7-Year cumulative rate, $\%$ & $p$ value & $\operatorname{HR}(95 \% \mathrm{CI})$ & $p$ value \\
\hline \multicolumn{5}{|l|}{ Baseline at diagnosis } \\
\hline Age, yr & & 0.001 & & \\
\hline$\geq 20$ & 36.3 & & Reference & \\
\hline$<20$ & 19.0 & & $2.13(1.22-3.70)$ & 0.008 \\
\hline Sex & & 0.032 & & \\
\hline Female & 16.7 & & Reference & \\
\hline Male & 22.1 & & $0.78(0.56-1.09)$ & 0.150 \\
\hline Body mass index, $\mathrm{kg} / \mathrm{m}^{2}$ & & 0.024 & & \\
\hline$\geq 23$ & 19.5 & & Reference & \\
\hline$<23$ & 23.6 & & $1.27(0.92-1.75)$ & 0.140 \\
\hline Family history of IBD & & 0.751 & & \\
\hline No & 24.0 & & Reference & \\
\hline Yes & $9 \cdot 3$ & & $0.50(0.12-2.05)$ & 0.333 \\
\hline Smoking status & & 0.434 & & \\
\hline No & 28.3 & & Reference & \\
\hline Yes & 26.1 & & $1.15(0.79-1.68)$ & 0.478 \\
\hline Disease activity at diagnosis & & 0.000 & & \\
\hline Mild & $15 \cdot 3$ & & Reference & \\
\hline Moderate & $45 \cdot 2$ & & $1,97(1.34-2.90)$ & 0.001 \\
\hline Severe & $42 \cdot 3$ & & $2.21(1.30-3.76)$ & 0.003 \\
\hline Montreal classification of extent of UC & & 0.000 & & \\
\hline E1 (ulcerative proctitis) & 7.1 & & Reference & \\
\hline E2 (left-sided UC) & 26.4 & & $2.80(1.66-4.72)$ & 0.000 \\
\hline E3 (extensive UC) & 34.1 & & $3.23(1.89-5.54)$ & 0.000 \\
\hline \multicolumn{5}{|l|}{ Treatment } \\
\hline UC-related admission & & 0.000 & & \\
\hline No & 8.5 & & Reference & \\
\hline Yes & 36.3 & & $0.98(0.62-1.53)$ & 0.915 \\
\hline UC-related operation & & 0.011 & & \\
\hline No & 18.9 & & Reference & \\
\hline Yes & 34.2 & & $1.16(0.67-2.02)$ & 0.591 \\
\hline \multicolumn{5}{|l|}{ Medication } \\
\hline Oral steroids & & 0.000 & & \\
\hline No & 1.1 & & Reference & \\
\hline Yes & $34 \cdot 7$ & & $26.72(6.71-114.58)$ & 0.000 \\
\hline IV steroids & & 0.000 & & \\
\hline No & 12.4 & & Reference & \\
\hline Yes & 56.6 & & $1.49(1.03-2.16)$ & 0.036 \\
\hline Infliximab & & 0.000 & & \\
\hline No & 16.1 & & Reference & \\
\hline Yes & 79.9 & & $3.02(2.11-4.30)$ & 0.000 \\
\hline
\end{tabular}

HR, hazard ratio; CI, confidence interval; IBD, inflammatory bowel disease; UC, ulcerative colitis; IV, intravenous. 
Supplementary Table 5 . Risk factors of ulcerative colitis-related operation in ulcerative colitis patients

\begin{tabular}{|c|c|c|c|c|}
\hline \multirow{2}{*}{ Characteristic } & \multicolumn{2}{|c|}{ Univariate analysis } & \multicolumn{2}{|c|}{ Multivariate analysis } \\
\hline & 7-Year cumulative rate, $\%$ & $p$ value & $\operatorname{HR}(95 \% \mathrm{CI})$ & $p$ value \\
\hline \multicolumn{5}{|l|}{ Baseline at diagnosis } \\
\hline Age, yr & & 0.430 & & \\
\hline$\geq 20$ & $5 \cdot 7$ & & Reference & \\
\hline$<20$ & 5.1 & & $1.45(0.41-5.17)$ & 0.567 \\
\hline Sex & & 0.389 & & \\
\hline Female & 4.8 & & Reference & \\
\hline Male & 3.0 & & $0.59(0.26-1.31)$ & 0.192 \\
\hline Body mass index, $\mathrm{kg} / \mathrm{m}^{2}$ & & 0.642 & & \\
\hline$\geq 23$ & 4.1 & & Reference & \\
\hline$<23$ & $4 \cdot 7$ & & $0.97(0.46-2.07)$ & 0.937 \\
\hline Family history of IBD & & 0.453 & & \\
\hline No & $4 \cdot 5$ & & Reference & \\
\hline Yes & 0.0 & & - & - \\
\hline Smoking status & & 0.537 & & \\
\hline No & $5 \cdot 9$ & & Reference & \\
\hline Yes & 3.6 & & $1.17(0.42-3.27)$ & 0.766 \\
\hline Disease activity at diagnosis & & 0.001 & & \\
\hline Mild & $3 \cdot 5$ & & Reference & \\
\hline Moderate & $4 \cdot 6$ & & $1.14(0.42-3.06)$ & 0.796 \\
\hline Severe & 13.1 & & $2.24(0.72-6.95)$ & 0.163 \\
\hline Montreal classification of extent of UC & & 0.000 & & \\
\hline E1 (ulcerative proctitis) & 2.0 & & Reference & \\
\hline E2 (left-sided UC) & 2.4 & & $0.70(0.24-2.02)$ & 0.507 \\
\hline $\mathrm{E}_{3}$ (extensive UC) & 8.2 & & $2.33(1.01-5.40)$ & 0.049 \\
\hline \multicolumn{5}{|l|}{ Treatment } \\
\hline UC-related admission & & 0.000 & & \\
\hline No & 0.7 & & Reference & \\
\hline Yes & 8.4 & & $6.94(1.50-32.21)$ & 0.013 \\
\hline \multicolumn{5}{|l|}{ Medication } \\
\hline \multicolumn{5}{|l|}{ Oral steroids } \\
\hline No & $3 \cdot 0$ & 0.029 & Reference & \\
\hline Yes & 4.8 & & $3.18(1.46-6.80)$ & 0.004 \\
\hline IV steroids & & 0.000 & & \\
\hline No & 1.8 & & Reference & \\
\hline Yes & 12.8 & & $2.62(1.14-6.05)$ & 0.024 \\
\hline Immunosuppressants & & 0.000 & & \\
\hline No & 2.2 & & Reference & \\
\hline Yes & 6.6 & & $0.83(0.37-1.86)$ & 0.645 \\
\hline Infliximab & & 0.246 & & \\
\hline No & 4.0 & & Reference & \\
\hline Yes & 1.2 & & $0.12(0.02-0.89)$ & 0.038 \\
\hline
\end{tabular}

HR, hazard ratio; CI, confidence interval; IBD, inflammatory bowel disease; UC, ulcerative colitis; IV, intravenous. 